\title{
Knowledge, Attitudes, Practices, and Behaviours on Malaria Prevention in Zambezia Province, Mozambique
}

\section{Liliana da Fonseca ( $\square$ liapinto83@gmail.com )}

Ordem dos Medicos de Mocambique https://orcid.org/0000-0001-9089-4375

Jorge Harrison Arroz

Mozambique Medical Council

Maria do Rosario 0. Martins

Universidade Nova de Lisboa Instituto de Higiene e Medicina Tropical

Zulmira Hartz

Universidade Nova de Lisboa Instituto de Higiene e Medicina Tropical

Nuria W Negrao

Cactus Communications Inc

Victor Muchanga

PIRCOM

Amadeu Cossa

PIRCOM

\section{Research}

Keywords: Knowledge, Attitude, Practices, Behavior, Beneficiaries, Malaria, Social and Behavior Change

Posted Date: September 10th, 2020

DOl: https://doi.org/10.21203/rs.3.rs-74134/v1

License: (c) (i) This work is licensed under a Creative Commons Attribution 4.0 International License.

Read Full License 


\section{Abstract}

Background: In Mozambique, the socio-economic and cultural factors influence the wide adoption of disease preventive measures, which is relevant for malaria control strategies that rely on early recognition of disease, prompt seeking of medical care, sleeping under mosquito nets, and taking intermittent preventive treatment for pregnant women. However, there is a critical information gap regarding to previous and ongoing malaria Social Behaviour Communication (SBC) interventions. The aim of this study is to assess the knowledge, attitudes, practices, and behaviours of the beneficiaries of SBC interventions.

Methods: A descriptive cross-sectional survey was undertaken in 2018 in two rural districts of Zambezia province, Mozambique. A structured questionnaire was administered to 773 randomly selected households. Respondents are the heads of the households, adults above 18 years old. Descriptive statistics were done.

Results: The main results show that around $96.4 \%$ respondents recalled hearing about malaria in the previous 6 months and $90.0 \%$ had knowledge on malaria prevention and $70.0 \%$ on preventive measures ; from $97.7 \%$ respondents that received bed nets through the mass bed net distribution campaign, $81.7 \%$ slept under a bed net the night before the survey; $70.5 \%$ recognized the role of community volunteers in the dissemination of malaria prevention messages; $76.1 \%$ of respondents considered worship places (churches and mosques) to be the main places where they heard key messages on malaria prevention and $79.1 \%$ asserted that community dialogue sessions helped them better understand how to prevent malaria.

Conclusions: Results show that the volunteers/activists/teachers have played an important role in the dissemination of key malaria prevention messages which brought the following successes: community actors are recognized and people have knowledge on malaria transmission, signs and symptoms, preventive measures, and where to get treatment. There is room for improvement on the SBC messaging regarding some malaria symptoms (anaemia and convulsions); and operational research is needed to ascertain the drivers of malaria prevalence and social and behaviour communication approach.

\section{Background}

In 2018 there were an estimated 228 million cases of malaria globally and the vast majority (93\%) were in the African region [1]. Mozambique, despite being a relatively small country, is one of the six countries that accounted for more than half of all malaria cases [1]. Therefore, it is important to understand the factors that contribute to such a high disease burden in the country.

The World Health Organization's Global Technical Strategy for malaria 2016-2030 is comprised of three major pillars with two supporting elements: (i) innovation and research, and (ii) a strong enabling environment [2]. These supporting elements are aligned with the Mozambican National Malaria Control Program (NMCP) agenda for the elimination of malaria trough implementation of research to optimize 
the impact and cost-effectiveness of new and existing tools, interventions and strategies, strong political and financial commitments, multi-sectorial approaches, stewardship of the health system, and capacity building development [3].

The NMCP prioritizes planning, implementation, monitoring, and evaluation based on an evidence-based, multi-cultural, and gender equality approach and an interpersonal communication and mass media (radio) approach [3]. However, there is a critical information gap about the outcomes and impact of social and behavioural change (SBC) interventions in Mozambique [3]. SBC interventions are widely used in malaria prevention and control programs (case management, mosquito nets, and indoor residual spraying) and play an important role by increasing knowledge and creating awareness and demand for prevention and treatment programs [4]. Human behaviour is an important factor contributing to disease burden [5]. Therefore, it is important to do formative research into various aspects that influence human behaviour, such as individual preferences, community characteristics, leadership practices, and quality of available goods and services to determine their impact and to design effective SBC strategies and interventions [5].

In Mozambique, the goal of research on SBC interventions is to identify knowledge, attitudes, practices, and behaviours of communities in order to define key strategies, target groups, cultural barriers, and community beliefs for improving malaria health outcomes through the adoption of positive health behaviours $[3,6]$. This finding is similar to a study conducted in rural Tanzania that demonstrated that more research on malaria knowledge and beliefs of the community is necessary to obtain and maintain community engagement and participation in malaria control activities [7]. The importance of obtaining this knowledge was underlined in a study conducted in South-Eastern Iran that showed that strategies for the control of malaria can be effective, useful, and valuable if prior studies are taken to explore and understand people's knowledge, attitudes, and practices [8]. In addition, and encouragingly, a study from rural Uganda indicated that communities with knowledge can influence the practices in households and support the control of the disease [9]. Thus, in areas with high burden of disease it is important to have a clear understanding of the community to design good SBC interventions and disseminate malaria prevention knowledge.

The present study was conducted with the aim of assessing the knowledge, attitudes, practices, and behaviours of the beneficiaries of malaria prevention SBC interventions in rural Mozambique.

\section{Methods}

\section{Study area and design}

This study was a cross-sectional survey carried out in November and December of 2018 in the Namacurra and Nicoadala districts of the Zambézia province. The districts were selected based on: i) malaria incidence; ii) accessibility; iii) population size similarities; iv) rural type; v) SBC interventions; vi) littoral and coastal. All the localities of these districts were selected for the study. Within each locality, 
household sample size was calculated by dividing the total sample size of the district by the number of existing localities. Households, the sampling units used in this study, were selected using a systematic random sampling method, after determining the total number in each locality.

\section{Sample}

Sample size was calculated based on the equation:

$n=Z^{2} \times p \times(1-p) / d(1)$

Where: $n=$ sample size; $Z=1.96$ (assuming a level of confidence of $95 \%$ ); $p=$ proportion $=0.5 ; d=$ error $=$ 0.05 . A total of 768 households were eligible for the study, 384 per district. The households were divided between localities with a size equal to the proportion of households per locality. Additionally, 5 households were added during the data collection process, resulting in a study population of 773 households.

\section{Selection Of Households}

In each locality, the households were selected based on the following strategy: first, a household list (population frame) was identified and a number was assigned to each household; then, the sample interval (number of households divided by sample size) was computed and a random number was chosen; finally, from this first random number, households were systematically selected until the calculated sample size was met.

\section{Data Collection And Measurement}

A structured questionnaire was pre-tested and administered by previously trained local inquirers. The first section of the questionnaire included socio-demographic questions and the following parts of the questionnaire assessed the head of the household regarding knowledge, attitudes, practices/behaviours, and information channels. The questionnaire was designed in Portuguese, but the interviews were conducted in the local language, Enlowe. The questionnaire was pre-tested in a district similar to the study districts. The head of the household was defined as the primary decision maker in the family and the household and as an individual living in the household and having meals from common cooking facility [15]. A responsible adult, 18-years or older, was appointed to participate in the interview in the absence of the head of the household.

\section{Variables}


The variables selected for this study were: place of residence, age, sex, level of education, number of people that live in the household, information channels, knowledge, attitudes, and practices regarding malaria.

\section{Household Inclusion Criteria}

The inclusion criteria used to select the households for the study were: i) households from the selected districts, ii) living in the district from 2011 to 2017 (this period covers the SBC interventions funded by different malaria donors), iii) interviewee with at last 18 years of age (head of the household), regardless of gender, iv) the presence of SBC interventions performed by local community actors (volunteers from community structures, school teacher facilitators, activists, and faith leaders), v) mosquito net mass distribution campaigns, and vi) presence of community radios.

\section{Outcomes Of Interest}

The measured outcomes were: i) percentage of people who remember hearing or seeing a message about malaria in the previous 6 months, ii) percentage of people with favourable attitudes towards the product (mosquito nets), practices (use of mosquito nets, taking antimalarial), or services (timely demand for health, institutional, or community services when noticing signs and symptoms of malaria), iii) percentage of people who believe that the majority of their friends and communities practice the behaviours (using mosquito nets and seeking counselling and health care services), iv) percentage of people who identify the mosquito as a cause/vector of malaria, $v$ ) percentage of people who recognize the main signs and symptoms of malaria, vi) percentage of people who know about treatment for malaria, vii) percentage of people who know malaria prevention measures, viii) percentage of households with at least one mosquito net, ix) percentage of households with 1 mosquito net for every 2 people, $x$ ) percentage of people with access to mosquito nets, $\mathrm{xi}$ ) percentage of people who slept under the mosquito net the night before the survey, and xii) use/access ratio of mosquito nets - behaviour indicator.

\section{Data And Statistical Analysis}

After conducting the study, the previously coded questionnaires were reviewed to verify the responses and their validation; later, the data were entered in a database of the program SPSS for Windows, version 23.0 (IBM; Armonk, NY, US). Data analysis was based on descriptive and inferential statistical analysis,

\section{Results}

\section{Socio-Demographic Characteristics of participants}


A total of 773 household heads were interviewed, $59 \%$ females and $41 \%$ males (Table 1 ). The mean age was 34.6 years (range: $18-90$ years), Standard Deviation of 7.7 . About $27.4 \%$ were illiterate, $63 \%$ were enrolled in primary school, and $8.4 \%$ were enrolled in basic education. About half of the respondents $(49.9 \%)$ lived in households with 4 to 6 people, little more than a quarter $(26.3 \%)$ in households composed of 1 to 3 members, and the remainder in households with 7 members or more (23.8\%). Detailed sociodemographic characteristics are presented in Table 1. 
Table 1

Socio-demographic characteristics of respondents in the selected households from Nicoadala and Namacurra.

\begin{tabular}{|c|c|c|}
\hline Characteristics & $N=773$ & Percentage (\%) \\
\hline \multicolumn{3}{|l|}{ Household size } \\
\hline 1 to 3 & 206 & $26.6 \%$ \\
\hline 4 to 6 & 385 & $49.8 \%$ \\
\hline$\geq 7$ & 182 & $23.5 \%$ \\
\hline Total & 773 & $100.0 \%$ \\
\hline \multicolumn{3}{|c|}{ Household members frequently present in the last 6 months } \\
\hline 1 to 3 & 203 & $26.3 \%$ \\
\hline 4 to 6 & 386 & $49.9 \%$ \\
\hline$\geq 7$ & 184 & $23.8 \%$ \\
\hline Total & 773 & $100.0 \%$ \\
\hline \multicolumn{3}{|l|}{ Sex } \\
\hline Male & 317 & $41.0 \%$ \\
\hline Female & 456 & $59.0 \%$ \\
\hline Total & 773 & $100.0 \%$ \\
\hline \multicolumn{3}{|l|}{ Age } \\
\hline$<18$ & 26 & $3.4 \%$ \\
\hline 18 to 24 & 209 & $27.0 \%$ \\
\hline 25 to 34 & 175 & $22.6 \%$ \\
\hline 35 to 49 & 206 & $26.6 \%$ \\
\hline 50 to 64 & 114 & $14.7 \%$ \\
\hline $65+$ & 27 & $3.5 \%$ \\
\hline Unknown & 16 & $2.1 \%$ \\
\hline Total & 773 & $100.0 \%$ \\
\hline \multicolumn{3}{|c|}{ High Level of Education Completed } \\
\hline No Education & 212 & $27.4 \%$ \\
\hline Primary and elementary & 487 & $63.0 \%$ \\
\hline
\end{tabular}




\begin{tabular}{|lll|}
\hline Characteristics & $\mathbf{N}=\mathbf{7 7 3}$ & Percentage (\%) \\
\hline Basic & 65 & $8.4 \%$ \\
\hline Secondary & 8 & $1.0 \%$ \\
\hline Tertiary and university & 1 & $0.1 \%$ \\
\hline Total & 773 & $100.0 \%$ \\
\hline
\end{tabular}

Community-wide levels of knowledge, attitudes, and practices regarding malaria prevention and treatment

Table 2 shows that within 773 household heads, about $96 \%$ had heard and $3.3 \%$ had never heard about malaria. Most respondents (96.4\%), recalled hearing about malaria in the previous 6 months.

Table 2

Reported exposure to information about malaria

\begin{tabular}{|lcl|}
\hline Variable & N & Percentage (\%) \\
\hline \multicolumn{2}{|l|}{ Ever heard of Malaria? } \\
\hline Yes & 695 & $96 \%$ \\
\hline No & 26 & $3.3 \%$ \\
\hline Without answer & 52 & $6.7 \%$ \\
\hline Total & 773 & $100.0 \%$ \\
\hline If yes, any exposure in the previous 6 months? \\
\hline Yes & 695 & $96.4 \%$ \\
\hline No & 26 & $3.6 \%$ \\
\hline Total & 721 & $100.0 \%$ \\
\hline
\end{tabular}

Most respondents (83.4\%) were aware of malaria being transmitted through mosquito bites. Regarding the recognition of malaria symptoms, headache was pointed to as one of the main symptoms of malaria by both male (48.9\%) and female (48.7\%) respondents. Body pain was the second most mentioned symptom by $39.1 \%$ of males and $34.2 \%$ of females. About $3.9 \%$ of respondents were unable to identify any symptoms of malaria. In Table 3, it can be noted that the most known malaria preventive measure is the use of insecticide-treated mosquito nets (72.2\%). More men (76\%) reported the use an insecticide treated mosquito net than women (70\%); burning garbage and creating smoke to chase away mosquitoes (35\%), and improving the cleanliness and hygiene of the house and yard (24\%), were other preventive measures mentioned by more than a fifth of respondents. Insecticide residual spraying was one of the least mentioned forms of prevention (4.3\%). The use of insecticide products and repellent were also rarely mentioned, $3.1 \%$ and $1.8 \%$, respectively. 
Table 3

Level of knowledge about malaria

\section{Type of Knowledge}

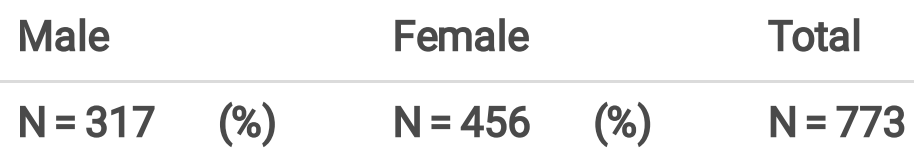

A. Knowledge on malaria transmission

\begin{tabular}{|lllllll|}
\hline Mosquito byte & 271 & $85.5 \%$ & 374 & $83.4 \%$ & 645 & $83.4 \%$ \\
\hline Garbage/dirt near the house & 84 & $26.5 \%$ & 135 & $29.6 \%$ & 219 & $28.3 \%$ \\
\hline Others (fleas/lice) & 49 & $15.5 \%$ & 67 & $14.7 \%$ & 116 & $15.0 \%$ \\
\hline Does not know & 17 & $5.4 \%$ & 31 & $6.8 \%$ & 48 & $6.2 \%$ \\
\hline B. Recognition of symptoms & & & & & & \\
\hline Body pain & 124 & $39.1 \%$ & 156 & $34.2 \%$ & 280 & $36.2 \%$ \\
\hline Headaches & 155 & $48.9 \%$ & 222 & $48.7 \%$ & 377 & $48.8 \%$ \\
\hline Joint pain & 74 & $23.3 \%$ & 133 & $29.2 \%$ & 207 & $26.8 \%$ \\
\hline Diarrhoea & 39 & $12.3 \%$ & 86 & $18.9 \%$ & 125 & $16.2 \%$ \\
\hline Vomit & 46 & $14.5 \%$ & 114 & $25.0 \%$ & 160 & $20.7 \%$ \\
\hline Lack of appetite & 49 & $15.5 \%$ & 80 & $17.5 \%$ & 129 & $16.7 \%$ \\
\hline Cough & 5 & $1.6 \%$ & 7 & $1.5 \%$ & 12 & $1.6 \%$ \\
\hline Nasal congestion & 1 & $0.3 \%$ & 1 & $0.2 \%$ & 2 & $0.3 \%$ \\
\hline Does not know & 9 & $2.8 \%$ & 21 & $4.6 \%$ & 30 & $3.9 \%$ \\
\hline C. Knowledge about preventive & measures & & & & $7.3 \%$ & \\
\hline Burn leaves/eucalyptus & 14 & $4.4 \%$ & 40 & $8.8 \%$ & 54 & $7.0 \%$ \\
\hline Insecticide Serpentine/Spray & 4 & $1.3 \%$ & 20 & $4.4 \%$ & 24 & $3.1 \%$ \\
\hline Mosquito net & 241 & $76.0 \%$ & 319 & $70.0 \%$ & 558 & $72.2 \%$ \\
\hline Repellent & 3 & $0.9 \%$ & 11 & $2.4 \%$ & 14 & $1.8 \%$ \\
\hline Burn garbage & 112 & $35.3 \%$ & 156 & $34.2 \%$ & 268 & $34.7 \%$ \\
\hline Traditional Treatment & 3 & $0.9 \%$ & 6 & $1.3 \%$ & 9 & $1.2 \%$ \\
\hline Improve home hygiene & 79 & $24.9 \%$ & 109 & $23.9 \%$ & 188 & $24.3 \%$ \\
\hline Spraying/fumigate the house & 8 & $2.5 \%$ & 25 & $5.5 \%$ & 33 & $4.3 \%$ \\
\hline Improve individual hygiene & 16 & $5.0 \%$ & 15 & $3.3 \%$ & 31 & $4.0 \%$ \\
\hline
\end{tabular}




\section{Type of Knowledge}

$\begin{array}{lllllll}\text { None/Does not know } & 23 & 7.3 \% & 42 & 9.2 \% & 65 & 8.4 \%\end{array}$

\section{Ownership and use of bed nets in the target communities}

About $80 \%$ of respondents reported having at least one bed net hanging at home, $21 \%$ reported having only one, $37.2 \%$ having two, $26.7 \%$ having three, and $13.3 \%$ having four or more. Most of the respondents $(97.7 \%)$ reported that they received the bed nets trough the mass bed net distribution campaign (Universal Coverage), and $81.7 \%$ reported sleeping under the bed net the night before the survey (Table 5).

Table 4

Treated bed net ownership

\begin{tabular}{|lcl|}
\hline Variables & N & Percentage (\%) \\
\hline Households that have at least one bed net hanging at home \\
\hline Yes & 618 & $79.9 \%$ \\
\hline No & 103 & $13.3 \%$ \\
\hline No answer & 52 & $6.7 \%$ \\
\hline Total & 773 & $100.0 \%$ \\
\hline Number of bed nets at home & & \\
\hline One bed net & 131 & $21.2 \%$ \\
\hline Two bed net & 230 & $37.2 \%$ \\
\hline Three bed net & 165 & $26.7 \%$ \\
\hline Four bed net & 53 & $8.6 \%$ \\
\hline Five or more & 29 & $4.7 \%$ \\
\hline Don't know & 10 & $1.6 \%$ \\
\hline Total & 618 & $100.0 \%$ \\
\hline Places where the bed net was acquired & \\
\hline Universal Coverage Campaign & 604 & $97.7 \%$ \\
\hline Antenatal Care & 4 & $0.6 \%$ \\
\hline Don't Know & 10 & $1.6 \%$ \\
\hline Other places & 0 & $0.0 \%$ \\
\hline Total & 618 & $100.0 \%$ \\
\hline
\end{tabular}


Table 5

Bed net usage

\begin{tabular}{|lllllll|}
\hline $\begin{array}{l}\text { Did someone sleep under a bed } \\
\text { net the night before }\end{array}$ & Male & \multicolumn{3}{c|}{ Female } & \multicolumn{3}{c|}{ Total } \\
\cline { 2 - 7 } & $\begin{array}{l}\text { FrEq. }(\mathbf{N} \\
\mathbf{3} 301)\end{array}$ & $\begin{array}{l}\text { Perc. } \\
(\%)\end{array}$ & $\begin{array}{l}\text { FrEq. } \\
=\mathbf{4 2 0})\end{array}$ & $\begin{array}{l}\text { Perc } \\
(\%)\end{array}$ & $\begin{array}{l}\text { FrEq. } \\
=\mathbf{6 1 8})\end{array}$ & $\begin{array}{l}\text { Perc. } \\
(\%)\end{array}$ \\
\hline Yes & 224 & $86.8 \%$ & 287 & $79.7 \%$ & 511 & $82.7 \%$ \\
\hline No & 34 & $13.2 \%$ & 73 & $20.3 \%$ & 107 & $17.3 \%$ \\
\hline
\end{tabular}

Knowledge, attitudes, and practices regarding malaria prevention and treatment of beneficiaries of SBC interventions

From the 721 respondents that reported exposure to information about malaria, $86.3 \%$ felt confident about their knowledge on how to prevent malaria and $96.4 \%$ knew where to get treatment. Regarding the use of bed nets at night, $96.9 \%$ of respondents considered it important to prevent from malaria. Most of the respondents $(69.2 \%)$ reported that family members, friends, and neighbours influence their decision making regarding their health and $23.6 \%$ disagreed with this assertion (Table 6). 
Table 6

Attitudes of beneficiaries regarding malaria prevention

\begin{tabular}{|lll|}
\hline Variables & N & Percentage (\%) \\
\hline I feel confident that I know how to prevent malaria & & \\
\hline Disagree or strongly disagree & 70 & $9.7 \%$ \\
\hline Neutral & 29 & $4.0 \%$ \\
\hline Agree or strongly agree & 622 & $86.3 \%$ \\
\hline Total & 721 & $100.0 \%$ \\
\hline I know where I can get treatment for malaria & & \\
\hline Disagree or strongly disagree & 16 & $2.2 \%$ \\
\hline Neutral & 10 & $1.4 \%$ \\
\hline Agree or strongly agree & 695 & $96.4 \%$ \\
\hline Total & 721 & $100.0 \%$ \\
\hline The use of a bed net every night is important so that I can protect myself from getting malaria \\
\hline Disagree or strongly disagree & 17 & $2.4 \%$ \\
\hline Neutral & 5 & $0.7 \%$ \\
\hline Agree or strongly disagree & 699 & $96.9 \%$ \\
\hline Total & 721 & $100.0 \%$ \\
\hline My family, friends, and neighbours influence my decision-making regarding my health \\
\hline Disagree or strongly disagree & 170 & $23.6 \%$ \\
\hline Neutral & 52 & $7.2 \%$ \\
\hline Agree or strongly agree & 499 & $69.2 \%$ \\
\hline Total & 721 & $100.0 \%$ \\
\hline & & \\
\hline
\end{tabular}

Table 7 shows attitudes regarding measures adopted for malaria diagnosis and febrile symptoms. From the 721 heads of household (beneficiaries of SBC interventions), 539 (74.8\%) reported some household member with a fever in the previous 6 months. From those, in 409 households, family members reported to have had a fever in the two weeks prior to this survey, and 395 reported seeking counselling and treatment from health facilities, 10 from the market, and 4 from other places. An important aspect to reflect on, was that the reason given for choosing the health facility services to treat malaria was that it was less expensive (22\%), and the person who decided where to seek counselling and treatment was the head of the household (72.9\%), followed by the wife of the head of household (16\%), and then the person with fever (9\%). From 395 households, 359 reported performing the rapid diagnostic test and the 
remaining 39 did not. Meanwhile, from the 359 respondents that did the test, $89.7 \%$ obtained a positive result, $0.8 \%$ negative, and $9.5 \%$ did not know the result 
Table 7

Beneficiaries' attitudes towards malaria diagnosis and treatment

\begin{tabular}{|c|c|c|}
\hline Variables & $\mathbf{N}$ & Percentage (\%) \\
\hline \multicolumn{3}{|c|}{ Has a household member had a fever in the previous 6 months } \\
\hline Yes & 539 & $74.8 \%$ \\
\hline No & 175 & $24.3 \%$ \\
\hline Does not know/Does not remember & 7 & $1.0 \%$ \\
\hline Total & 721 & $100.0 \%$ \\
\hline \multicolumn{3}{|c|}{ Has a household member had a fever in the previou two weeks } \\
\hline Yes & 409 & $56.7 \%$ \\
\hline No & 273 & $37.9 \%$ \\
\hline Does not know/Does not remember & 5 & $0.7 \%$ \\
\hline Total & 687 & $95.3 \%$ \\
\hline \multicolumn{3}{|c|}{ Where did you seek counselling and treatment } \\
\hline Health Facility & 395 & $96.6 \%$ \\
\hline Market & 10 & $2.4 \%$ \\
\hline Another place & 4 & $1.0 \%$ \\
\hline Total & 409 & $100.0 \%$ \\
\hline \multicolumn{3}{|c|}{ The reason you sought advice or treatment from this provider } \\
\hline More efficient / competent/better quality & 261 & $66 \%$ \\
\hline Less expensive & 87 & $22.0 \%$ \\
\hline Close to their residency & 36 & $9.0 \%$ \\
\hline Other reason & 11 & $3.0 \%$ \\
\hline Total & 395 & $100.0 \%$ \\
\hline \multicolumn{3}{|c|}{ Who decided where you went to for counselling/treatment } \\
\hline Head of Household & 290 & $72.9 \%$ \\
\hline Wife of the head of household & 67 & $16.8 \%$ \\
\hline Mother-in-law & 1 & $0.3 \%$ \\
\hline The person with the fever & 36 & $9.0 \%$ \\
\hline Other & 4 & $1.0 \%$ \\
\hline
\end{tabular}

Page $14 / 22$ 


\begin{tabular}{|lll|}
\hline Variables & N & Percentage (\%) \\
\hline Total & 395 & $100.0 \%$ \\
\hline Did malaria test & & \\
Yes & 359 & $90.2 \%$ \\
\hline No & 39 & $9.8 \%$ \\
\hline Total & 395 & $100.0 \%$ \\
Know about malaria test result & & \\
Positive & 322 & $89.7 \%$ \\
Negative & 3 & $0.8 \%$ \\
Do not know & 34 & $9.5 \%$ \\
\hline Total & 359 & $100.0 \%$ \\
\hline
\end{tabular}

Communication channels (source of information) about malaria prevention and treatment in the community, its potentials and limitations

As shown in Table 8, around $70.5 \%$ of respondents felt that community volunteers were ready to disseminate key malaria prevention messages. From 721 respondents, 76.1\% considered worship places (churches and mosques) to be the main places where they heard key messages on malaria prevention. Meanwhile, $79.1 \%$ strongly agreed that community dialogue sessions helped them better understand how to prevent malaria. For the respondents, volunteers/activists/teachers played an important role in the dissemination of key malaria prevention messages. 
Table 8

Attitudes of beneficiaries regarding malaria prevention

\begin{tabular}{lcc}
\hline Variables & N & \multicolumn{2}{c}{ Percent } \\
\hline I feel that community volunteers are prepared to spread key malaria prevention \\
\hline Disagree or strongly disagree & 86 & $11.9 \%$ \\
\hline Neutral & 76 & $10.5 \%$ \\
\hline Agree or strongly agree & 559 & $77.5 \%$ \\
\hline Total & 721 & $100.0 \%$ \\
\hline Did you receive sufficient information from the activists? & & \\
\hline Disagree or strongly disagree & 113 & $15.7 \%$ \\
\hline Neutral & 102 & $14.1 \%$ \\
\hline Agree or strongly agree & 506 & $70.2 \%$ \\
\hline Total & 721 & $100.0 \%$
\end{tabular}

Most of my neighbours, my community, and my family including myself have the ability to recognize the signs and symptoms of malaria

\begin{tabular}{lll} 
Disagree or strongly disagree & 90 & $12.5 \%$ \\
\hline Neutral & 46 & $6.4 \%$ \\
\hline Agree or strongly agree & 585 & $81.1 \%$ \\
Total & 721 & $100.0 \%$
\end{tabular}

Worship places (churches and mosques) are where I hear malaria prevention messages

\begin{tabular}{lll} 
Disagree or strongly disagree & 133 & $18.4 \%$ \\
\hline Neutral & 39 & $5.4 \%$ \\
\hline Agree or strongly agree & 549 & $76.1 \%$ \\
\hline Total & 721 & $100.0 \%$
\end{tabular}

Community dialogue sessions helped me better understand how to prevent malaria

\begin{tabular}{lll} 
Disagree or strongly disagree & 65 & $9.0 \%$ \\
\hline Neutral & 86 & $11.9 \%$ \\
\hline Agree or strongly agree & 570 & $79.1 \%$ \\
\hline Total & 721 & $100.0 \%$
\end{tabular}

Volunteers/activists/teachers play a key role in spreading key messages on malaria prevention 


\begin{tabular}{|lll|}
\hline Variables & $\mathbf{N}$ & Percentage (\%) \\
\hline Disagree or strongly disagree & 55 & $7.6 \%$ \\
\hline Neutral & 65 & $9.0 \%$ \\
\hline Agree or strongly agree & 601 & $83.4 \%$ \\
\hline Total & 721 & $100.0 \%$ \\
\hline
\end{tabular}

\section{Discussion}

Most malaria prevention strategies are centred on human behaviour. Therefore, SBC interventions are a key part of the NMCP. This study aimed to assess the knowledge, attitudes, and practices regarding the prevention and treatment of malaria in two rural Mozambican districts, Namacurra and Nicoadala. The estimated population of Namacurra and Nicoadala is 390,410 and 270,825 inhabitants, respectively [10]. Both are rural districts with more than $60 \%$ of the population being illiterate and living in low social and economic conditions. The main public health problems are: malaria, HIV, and diarrheal diseases [11, 12]. In 2017, the incidence of malaria (per 1000 inhabitants) in Namacurra was 272, and in Nicoadala was 506 [13].

Our results show that almost all respondents had heard about malaria in the previous 6 months and that people in rural Zambezia province have at least some knowledge about malaria causes, symptoms, treatment, and preventive measures. These results are similar to those obtained in other studies $[7-9,14]$, implying that the SBC campaigns of the previous years have been successful at reaching people in rural Mozambique and somewhat successful at disseminating the education messages. However, it is important to note that although most respondents knew that malaria is transmitted by the mosquito bite, they did not associate it with other people (i.e., with "bites of mosquito which bit a malarial patient"). This lack of knowledge has also been reported before [8, 14], and is an indication that messaging on this aspect of transmission needs to be improved. Headaches were identified as the main symptom of malaria, similar to a study conducted by Khumbulani et al. [15]. However, despite relatively good knowledge on malaria symptoms and signs, the respondents failed to name anaemia and convulsions. This lack of information could lead to a delay in seeking appropriate care from health facilities or community health workers. Therefore, it is important to improve the training of local health community actors and subsequently improve the dissemination and explanation to the beneficiaries.

Most respondents felt confident and knew about malaria prevention methods and where to seek treatment, and considered the use of bed nets important to prevent and protect from malaria, similar to a study conducted in Ethiopia where the majority of respondents considered the mosquito net a protective measure against mosquito bites [16]. Long-lasting insecticidal nets (LLINs) are a key part of malaria prevention strategies. LLINs are distributed through key channels, $80 \%$ through mass distribution campaigns, $10 \%$ in antenatal care consultations, and $6 \%$ at integrated immunization campaigns [1]. In Mozambique $68 \%$ of the population sleeps under a bed net ( $40 \%$ under LLINs) and $41 \%$ of pregnant 
women receive all three doses of the intermittent preventive treatment (IPT3) [14]. Our results show that previous SBC campaigns on bed nets have been successful in rural Zambezia as these were among the most recognized prevention forms among the respondents, most of them having at least one bed net hanging at home which they use every night. Additionally, most reported sleeping under a bed net the night before the survey, which is similar to other studies conducted in the country $[7,14,17]$.

Interestingly, despite wide availability of bed nets in the region and the indication from our results that the community uses them, the prevalence of malaria in this region (Zambezia province) is 44\% in 2018 [14]. Similarly, the national malaria prevalence in children aged 6 to 59 months (using the malaria diagnostic test) increased from 38.3\% in 2011 [18], 40.2\% in 2015 [19] and 39\% in 2018 [14]. This seems to indicate that the use of bed nets in the region has reached its maximum potential impact for malaria prevention and that additional strategies will have to be implemented for a further reduction in prevalence.

In this study, health facilities were the most common source used for malaria treatment. This observation was similar to other studies [7,20], and it was pointed out as being the less expensive place to go to. The decision about where to go to receive treatment was the responsibility of the head of the household. The data shows that family members, friends, and neighbours were the greatest influencers on decision makers regarding questions about the health of the members of the household, similar to a study conducted in Nigeria, were it was indicated that family members play a role on health decisions [21]. This reinforces the importance of having high levels of education in communities.

The majority of respondents consider that the community volunteers/activists/teachers are very well trained and that they play an important role in disseminating key malaria preventive messages. Our findings are collaborated by a study conducted in Kenia which showed that community actors are very well accepted during community implementation of SBC interventions [22]. Worship places (churches and mosques) are where respondents heard malaria preventive messages, and community dialogue sessions helped them better understand how to prevent malaria. Similarly, in a study conducted in Nampula Province, Mozambique, respondents affirmed that community dialogues helped communication and ultimately encouraged malaria-related behaviors [23]. These results indicate that the people implementing SBC interventions in Mozambique aid in the dissemination of the information and are accepted interlocutors by the beneficiaries.

Our study targeted the head of household as a proxy to the knowledge, attitudes, and practices held by all members of the household. Ideally, the research team should have interviewed every adult in Nicoadala and Namacurra, which was not possible due to funding constraints. Therefore, the results may not accurately represent the community's perspectives as a whole.

\section{Conclusions}

Our study confirms that the SBC interventions carried out in rural Mozambique have had many successes. Namely, most people have knowledge about malaria prevention and treatment. Importantly, our study shows that beneficiaries know where to get bed nets and there is wide community acceptance 
of the use of bed nets. Beneficiaries recognized the role of community actors (teachers, community health workers, and religious leaders) in the dissemination of malaria key preventive messages. We identified that there is room for improvement on the SBC messaging regarding malaria symptoms. Specifically, it is important that people recognize anaemia and convulsions as malaria symptoms so that they are quick in seeking health care services. Moreover, our study raises the need for further research into the main drivers of malaria prevalence in the country but also the need to conduct operational research to refine the SBC approaches.

\section{Abbreviations}

HH: household; LLIN/LLINs: long-lasting insecticidal nets; SBCC: Social Behavior Communication Change; UCC: Universal Coverage Campaign; ANC: Antenatal care

\section{Declarations}

\section{Ethics approval}

The study was administratively authorized by the Provincial Health Directorate of Zambezia and also received authorization from the National Committee on Bioethics in Health (Ref 308/CNBS/2018).

The participants were informed about the objectives of the study. They signed an informed consent document to ensure the willingness of participation and they were free to withdraw from the study at any time. Identification numbers were used instead of participant names to maintain the confidentiality throughout the study.

\section{Consent for publication}

Not applicable.

\section{Availability of data and materials}

The datasets used and/or analysed during the current study are available from the corresponding author upon reasonable request.

\section{Competing interests}

The authors declare that they have no competing interests.

\section{Authors' contributions}

LP conceived and designed the study protocol, analysed the data, drafted the manuscript, and made final revisions. JA and MROM supported the protocol design, performed sample calculations, analysed data, and reviewed the manuscript. RZ supported the design of data collection tools and reviewed the manuscript. ZH critically reviewed the manuscript. VM and AM analysed the data and reviewed the 
manuscript. NN contributed to the writing, editing, and revision of the manuscript. All authors read and approved the final manuscript.

\section{Acknowledgements}

The authors would like to acknowledge the contributions of the anonymous community members who participated in the interviewing process. They would like to especially thank the household heads for participating in this study. The authors also would like to acknowledge the Zambezia health authorities for the administrative authorization for the study.

\section{Funding}

This study was funded by the Principal Investigator as part of her Ph.D. thesis. The findings and conclusions in this report are those of the authors.

\section{Competing interests}

The authors declare that they have no competing interests.

\section{References}

1. World Malaria Report. Geneva: World Health Organization; 2019. Available from: https://www.who.int/publications-detail/world-malaria-report-2019. Accessed 29 January 2020.

2. Global Technical Strategy for malaria 2016-30. Geneva 2015. Available in: https://www.who.int/malaria/areas/global_technical_strategy/en/. Accessed 20 September 2019.

3. Ministério da Saúde: National Malaria Controlo Programme. Malaria Strategic Plan 2017-2022, 2017. Maputo, Mozambique (UNPUBLISHED).

4. Zalisk et al. Caregiver exposure to malaria social and behaviour change messages can improve bed net use among children in an endemic country: secondary analysis of the 2015 Nigeria Malaria Indicator Survey. Malaria Journal, 2019. 18:121

5. President Malaria Initiative. Malaria Initiative Technical Guidance, 2018

6. Roll Back Malaria Partnership to End Malaria. The Strategic Framework for Malaria Social and Behavior Change Communication 2018-203. Available in: Accessed 29 January 2020.

7. D. Mazingo et al. Knowledge, Attitude, and Practices about Malaria and its control I Rural Northwest Tazania, Malaria Research and Treatment, volume 2010, Article ID 794261,9 pages doi: $10.4061 / 2010 / 794261$

8. Nejati, J., Moosa-Kazemi, S.H., Saghafipour, A. et al. Knowledge, attitude and practice (KAP) on malaria, from high malaria burden rural communities, southeastern Iran. J Parasit Dis 42, 62-67 (2018). https://doi.org/10.1007/s12639-017-0965-8

9. Musoke, G. Karani, J. C. Sempebwa, S. Etajak1, D. Guwatudde, M. B. Musoke., "Knowledge and practices on malaria prevention in two rural communities in Wakiso District, Uganda", African Health 
Sciences Vol 15 Issue 2, June 2015

10. Ministerio da Administracao Estatal. Perfil do distrito de Nicoadala, 2014. Available from: http://www.maefp.gov.mz/wp-content/uploads/2017/04/Nicoadala.pdft. [Accessed in 8 February 2020]

11. Ministerio da Administração Estatal. Perfil do distrito de Namacurra, 2014. Available from: http://www.maefp.gov.mz/wp-content/uploads/2017/04/Namacurra.pdf. [Available in 8 February 2020]

12. Ministério da Saúde. Programa Nacional de Control da Malaria. Direção Provincial de Saúde Zambézia. Relatório anual. Boletim Epidemiológico de Saúde (BES), SISMA, 2017.

13. M. Ahmed, R. Haque, U. Haque, and A. Hossain, "Knowledge on the transmission, prevention and treatment of malaria among two endemic populations of Bangladesh and their health-seeking behaviour," Malaria Journal, vol. 8, no. 1, article 173, 2009.

14. Instituto Nacional de Saúde (INS). Inquérito Nacional Sobre Indicadores de Malária 2018. Maputo, Moçambique.

15. Hlongwana KW, Mabaso ML, Kunene S, Govender D, Maharaj R. Community knowledge, attitudes and practices (KAP) on malaria in Swaziland: a country earmarked for malaria elimination. Malar J. 2009;8:29. Published 2009 Feb 19. doi:10.1186/1475-2875-8-29

16. Astatkie A. Knowledge and practice of malaria prevention methods among residents of arba minch town and arba minch zuria district, southern ethiopia. Ethiop J Health Sci. 2010;20(3):185-193. doi:10.4314/ejhs.v20i3.69448

17. Arroz JAH, Candrinho B, Mendis C, Varela P, Pinto J, Martins MDRO. Effectiveness of a new longlasting insecticidal nets delivery model in two rural districts of Mozambique: a before-after study. Malar J. 2018;17(1):66. Published 2018 Feb 5. doi:10.1186/s12936-018-2217-5

18. República de Moçambique, Ministério da Saúde, Instituto Nacional de Estatística; MEASURE DHS/ICF International. Inquérito demográfico e de saúde 2011. Maputo, MZ; 2011. Available from: http://www.dhsprogram.com/pubs/pdf/FR266/FR266.pdf [Accessed 19th September 2017].

19. Ministério da Saúde (MISAU), Instituto Nacional de Estatística (INE), ICF Internacional, 2015. Inquérito de Indicadores de Imunização, Malária e HIV/SIDA em Moçambique 2015. Maputo, Moçambique. Rockville, Maryland, EUA: INS, INE e ICF International.

20. Sumba PO, Wong SL, Kanzaria HK, Johnson KA, John CC. Malaria treatment-seeking behaviour and recovery from malaria in a highland area of Kenya. Malar J. 2008;7:245. Published 2008 Nov 26. doi:10.1186/1475-2875-7-245

21. Campbell TH, McDaniel SH, Cole-Kelly K. Family issues in Health care. In: Taylor RB, editor. Family Medicine Principles and Practices. 6th ed. New York: Springer-Verlag; 2002. p. 24.

22. Owek, C.J., Oluoch, E., Wachira, J. et al. Community perceptions and attitudes on malaria case management and the role of community health workers. Malar J 16, 272 (2017). https://doi.org/10.1186/s12936-017-1916-7 
23. Hildon, Z.J., Escorcio-Ymayo, M., Zulliger, R. et al. "We have this, with my husband, we live in harmony": exploring the gendered decision-making matrix for malaria prevention and treatment in Nampula Province, Mozambique. Malar J 19, 133 (2020). https://doi.org/10.1186/s12936-02003198-5 